\title{
Is adenomyosis, a frequent association of abnormal uterine bleeding? : a retrospective study on hysterectomy samples in the rural area of Melmaruvathur
}

\author{
Sumathi S.* \\ Department of Pathology, MAPIMS, Melmaruvathur, Tamilnadu, India \\ Received: 15 February 2016 \\ Accepted: 08 March 2016 \\ *Correspondence: \\ Dr. Sumathi S., \\ E-mail: mr.rathinamari@rediffmail.com
}

Copyright: (c) the author(s), publisher and licensee Medip Academy. This is an open-access article distributed under the terms of the Creative Commons Attribution Non-Commercial License, which permits unrestricted non-commercial use, distribution, and reproduction in any medium, provided the original work is properly cited.

\begin{abstract}
Background: Abnormal uterine bleeding is one of the common gynecological problem and the causes varies among different age groups. The objective of the study was to find the prevalence of adenomyosis among hysterectomy samples of rural patients and associated pathological lesions as a cause for abnormal uterine bleeding.

Methods: A retrospective cross sectional study was carried out in pathology department of Melmaruvathur Adhiparasakthi institute of medical sciences from Jan 2014 to Dec 2015.A total of 82 hysterectomy samples operated for abnormal uterine bleeding were analyzed both grossly and microscopically.

Results: The common pathology noted was adenomyosis $56 \%$ followed by leiomyoma $35 \%$. The mean age of patients commonly affected was 45.86 years with a confidence interval of $95 \%$ (43-46years).

Conclusions: Adenomyosis is a frequent association of abnormal uterine bleeding and it commonly affects perimenopausal age group patients of 43-46years. Benign pathology is a frequent finding and malignant lesion is very rare.
\end{abstract}

Keywords: Abnormal uterine bleeding, Adenomyosis, Hysterectomy, DUB

\section{INTRODUCTION}

Hysterectomy is one of the common major surgeries performed in gynaecology. Abnormal uterine bleeding (AUB) is a common complaint for which many patients undergo hysterectomy. ${ }^{1}$ It can occur anytime in reproductive age group as heavy menstrual bleeding to post-menopausal bleeding. The international federation of Gynecology and Obstetrics (FIGO) has approved a new classification system of PALM-COEIN as a cause of abnormal uterine bleeding. PALM refers to structural abnormalities and COEIN are the non-structural causes of abnormal uterine bleeding as follows.

\begin{tabular}{|ll|}
\hline Polyp & Coagulopathy \\
\hline Adenomyosis & Ovulatory dysfunction \\
\hline Leiomyoma & Endometrial \\
\hline Malignancy \& hyperplasia & Iatrogenic \\
\hline & None classified \\
\hline
\end{tabular}

Leiomyoma and adenomyosis are the two common conditions which are associated with AUB and their frequency differs in different parts of the world. The purpose of this study is to find the prevalence of adenomyosis and the causes of AUB in patients of different age groups who underwent hysterectomy for AUB in rural area of Melmaruvathur, Tamil Nadu, South India.

\section{METHODS}

This was a retrospective cross sectional study carried out on hysterectomy samples of varying age grouped patients who underwent abdominal hysterectomy for abnormal uterine bleeding. This descriptive study was done in the pathology department of Melmaruvathur AdhiParasakthi institute of Medical sciences, Melmaruvathur at Tamil Nadu, South India from Jan 2014 to Dec 2015. Hysterectomy done for prolapsed uterus, pelvic 
inflammatory diseases, ovarian tumors and endometrial curetting biopsy sample for AUB were excluded from this study. The hysterectomy samples were fixed in $10 \%$ formalin. After detailed gross examination, tissue bits from endometrium, myometrium, and cervix were processed routinely and 3-4 micron thick sections were prepared from paraffin embedded tissue. These sections were stained with hematoxylin and eosin and carefully studied to elicit the cause of AUB. All the specimens were examined by same pathologist and the diagnosis was made based on the gross and microscopic appearance of the specimen. Then, the overall prevalence of adenomyosis in each age group, other associated pathological lesions were determined and the causes of AUB were analysed.

\section{RESULTS}

Table 1: The histopathological pattern of endometrium in AUB.

\begin{tabular}{|lll|}
\hline Histological pattern & Number & $\%$ \\
\hline Proliferative & 52 & $63 \%$ \\
\hline Disordered proliferative & 10 & $12 \%$ \\
\hline Iatrogenic pill changes & 9 & $11 \%$ \\
\hline $\begin{array}{l}\text { Simple hyperplasia without } \\
\text { atypia }\end{array}$ & 6 & $7 \%$ \\
\hline Atrophic & 4 & $5 \%$ \\
\hline Simple hyperplasia with atypia & 1 & $1 \%$ \\
\hline
\end{tabular}

Table 2: The histopathological pattern of myometrium in different age groups.

\begin{tabular}{|lllll|}
\hline Age group & $\begin{array}{l}\text { Leiomyoma } \\
\text { (Total 14 cases 17\%) }\end{array}$ & $\begin{array}{l}\text { Adenomyosis Total } \\
31 \text { cases 38\%) }\end{array}$ & $\begin{array}{l}\text { Dual pathology } \\
\text { Total 15 cases 18\%) }\end{array}$ & $\begin{array}{l}\text { Others } \\
\text { Total 22 cases 27\%) }\end{array}$ \\
\hline 30-40years & $14 \%$ & $10 \%$ & $0 \%$ & $18 \%$ \\
\hline $40-50$ years & $50 \%$ & $65 \%$ & $80 \%$ & $68 \%$ \\
\hline $50-60$ years & $29 \%$ & $26 \%$ & $20 \%$ & $14 \%$ \\
\hline$>60$ years & $7 \%$ & $0 \%$ & $0 \%$ & $0 \%$ \\
\hline
\end{tabular}

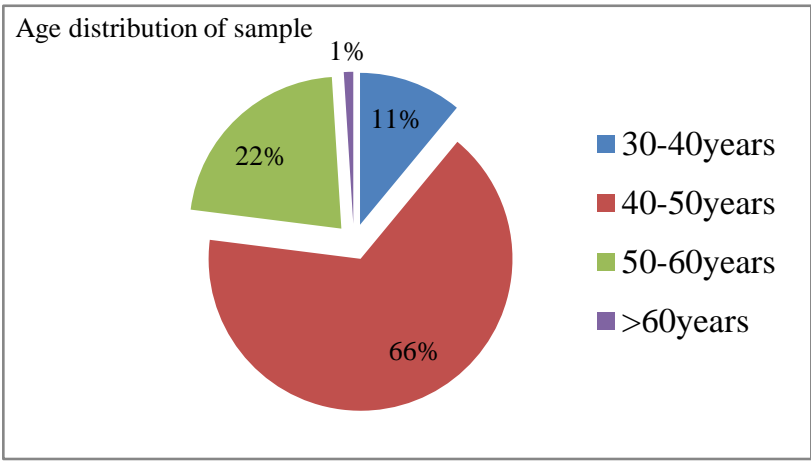

Figure 1: Age distribution of sample $(n=82)$.

A total of 82 samples were analysed in this study. Age of the patients ranged from 30-65 years and predominant group $(n=54)$ was perimenopausal age of $40-50$ years contributing to $66 \%$ of total cases in this study (Figure 1). Endometrial pathology of all the samples showed features of hyperestrogenic state predominantly in the form of proliferative endometrium $(\mathrm{n}=52, \mathrm{P}-63 \%)$ and only one case was reported as simple hyperplasia with atypia (Table 1). No malignant lesion of endometrium and cervix was noted in our study. The myometrial histopathological reports of samples were as follows. Adenomyosis alone $(\mathrm{n}=31) 38 \%$, Leiomyoma alone $(n=14) 17 \%$, and $18 \%$ showed dual pathology of adenomyosis and leiomyoma $(n=15)$ (Table 2). Bulky uterus and myohyperplasia was noted in 6 cases and the rest of samples $(n=16)$ showed no myometrial pathology. In perimenopausal age group of 40-50years adenomyosis $(n=20)$ was the common pathology $65 \%$ followed by leiomyoma $(n=7) 50 \%$. Dual pathology of adenomyosis and leiomyoma $(\mathrm{n}=12)$ was noted as $80 \%$ (Figure 2$)$.

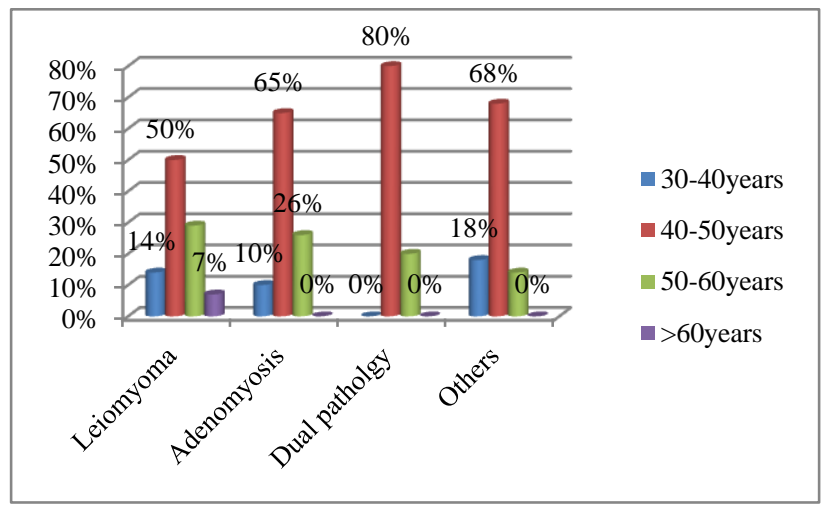

Figure 2: The histopathological pattern of myometrium in different age groups.

In this study adenomyosis was the frequently associated cause of AUB in patients who underwent hysterectomy between 40-50years of age. All endometrial pathology was related to hyperestrogenic state and no malignancy was noted in this study.

\section{DISCUSSION}

Abnormal uterine bleeding is defined as bleeding from uterine corpus that is abnormal in volume, timing and regularity. ${ }^{2}$ It is a common gynaecological problem 
accounting for up to $20 \%$ of the visits to Gynecologists. ${ }^{3}$ There are various causes of AUB in different age groups and management differs according to the cause. But still hysterectomy remains the widely accepted and practiced treatment of choice. Many studies done on hysterectomy samples showed increased frequency of leiomyoma as an indication for surgery. ${ }^{4-7}$ Adenomyosis is a myometrial lesion characterised by the presence of endometrial glands and stroma in the myometrium surrounded by myometrial hypertrophy and hyperplasia., ${ }^{8,9}$ The prevalence of both of it differs in different parts of the world. In this study the most common associated pathology in AUB was adenomyosis 56\% which is similar and supported by studies done by Ghazala in Kumaon, Maryam in Southern Iran. ${ }^{10,11}$ The prevalence of adenomyosis in their study was $46.34 \%$ and $50 \%$ respectively. The prevalence of leiomyoma in this study was $35 \%$ which is in contrast with the other study done by Sreeja who got the result of $78 \% .^{1}$ Most of the affected populations $(66 \%)$ in this study were belonging to perimenopausal age group with a mean age of 45.8years which is similar to other studies. ${ }^{1,3,10,12,13}$ But it is in contrast with one study which showed AUB was common among less than 20years of age and dysfunctional uterine bleeding was the frequent association in that age group. ${ }^{14}$ Many studies done on endometrial pathology in AUB patients revealed predominantly benign pathology related with hyperestrogenic state when compared to malignancy. ${ }^{15,16}$ This study also showed similar findings and no malignancy was noted. Various molecular studies were done on the pathogenesis of adenomyosis. ${ }^{17-19}$ It showed that the initiating culprit was estrogen which increases ANXA 2, IL-22 expression on endometrial stromal cells that promote invasion and progression of adenomyosis. It promotes progression by stimulating increased elaboration of VEGF and other angiogenic mediators. The usual clinical presentation of adenomyosis are dysmenorrhoea, menorrhagia, metrorrhagia and even miscarriages thereby affect the physical, mental and social wellbeing of the patients The exact reason for increased frequency of abnormal uterine bleeding in adenomyosis is not well understood. Possible mechanisms include impaired uterine contractility and compression as well as dysfunction of prostaglandins. ${ }^{20} \mathrm{I}$ Support this view and had a personal experience of increased effectiveness of anti-inflammatory drugs for this problem. This anti prostaglandin relieved the pain completely and reduces the quantity of bleeding by counteracting the increased vascular permeability brought about by prostaglandins. Though, medical and minimal invasive managements are there for AUB, nowadays hysterectomy is the widely practiced and preferred treatment among patients to prevent anaemia and to overcome the fear of malignancy. All surgeries have its own acute and chronic complications. So the further work can be done regarding the effectiveness of antiinflammatory drugs as a medical management for this. I also suggest a comparative study on physical, psychological, sexual morbidity in patients with AUB before and after hysterectomy.

\section{CONCLUSION}

This study concludes that the most common pathology associated with AUB among rural patients was adenomyosis followed by leiomyoma. The peak incidence of it occurs in perimenopausal age group (mean age of 45.86years) in this rural part of India.

\section{ACKNOWLEDGEMENT}

The author is thankful to Mr. Ashok, the statistics department of MAPIMS for helping in collecting the statistics.

\section{Funding: Not required}

Conflict of interest: None declared

Ethical approval: The study was approved by the Institutional Ethics Committee

\section{REFERENCES}

1. Sreeja Rani V, Thomas S. Leiomyoma, A major cause of abnormal uterine bleeding. Journal of Evolution of Medical and Dental sciences. 2013;2(16):2626.

2. Munro MG, Critchley HO, Broder MS, Fraser IS. FIGO Working Group on Menstrual Disorders. FIGO Classification system (PALM-COEIN) for causes of abnormal uterine bleeding in non gravid women of reproductive age. Int Gynaecol Obstet. 2011;113(1):3.

3. Niaz M, Chandi K, Amir MB, Tareen S. A Morphological study of Atypical uterine bleeding. Medical Forum Monthly. 2015;26(2):44-7.

4. Karthikeyan TM, Veena NN, Ajeeth Kumar CR. Clinicopathological study of hysterectomy among rural patients in a tertiary care center.IOSR Journal of Dental and Medical sciences. 2015;14(1):25-7.

5. Chaturvedi V, Dayal S, Srivastava D, Gupta V, Chandra A. Pattern and frequency of uterine pathologies among hysterectomy specimens in rural part of northern India: a retrospective secondary data analysis. Indian Journal of Community health. 2014;26(1):103-6.

6. Thamilselvi R, Pammy S, Subramanium. Correlation between clinic-pathological and Ultrasonographical findings in hysterectomy. 2011;5(4):737-40.

7. Chanderdeep S, Manupriya S, Rashmi R, Anjali S, Bal C, Suresh V. Gynecological diseases in rural india: A critical appraisal of indications and route of surgery along with histopathology correlation of 922 women undergoing major gynecological surgery. Midlife health. 2014;5(2):55-61.

8. Parrott Parrott E, Butterworth M, Green A, White IN, Greaves P.Adenomyosis-a result of disordered stromal differentiation. Am J Pathol. 2001;159:62330 . 
9. Naftalin J, Hoo W, Pateman K, Mavrelos D,X.Foo, Jurkovic D. Is adenomyosis associated with menorrhagia? Human Reproduction. 2014;29(3):4739.

10. Ghazala R, Harishankar P, Hema P,Sanjay SC,Prabhat P.Histopathological correlation of adenomyosis and leiomyoma in hysterectomy specimens as the cause of abnormal uterine bleeding in women in different age groups in the Kumaon region: A retrospective study. Midlife Health. 2013;4(1):27-30.

11. Maryam DM, Ahmadreza M, Iran R. Adenomyosis among samples from hysterectomy due to abnormal uterine bleeding in Ahwaz, South Iran. Adv Biomed Res. 2012;1:49.

12. Fatima A, Hooja N, Mital P, Nayan S, Nawal R, Aseri S. Analysis of profile of hysterectomies for abnormal uterine bleeding.Scholars Academic Journal of Biosciences. 2014;2(12C):960-2.

13. Mahmoud K, Masha S, Azam MT. Histopathological study of hysterectomy operations in a university clinic in Tehran from 2005-2009. Journal of Family and Reproductive Health. 2011;5(2):53-7.

14. Sedhai LB, Shrestha A. Abnormal uterine bleeding; Its prevalence, causes and management in Chitwan. Journal of Chitwan medical college. 2012;1(2):36-8.

15. Saraswathi D, Thanka J, Shajinee R, Aarthi R, Jaya V, Vinod Kumar P. Study of endometrial pathology in abnormal uterine bleeding. Journal of Obstet Gynecol India. 2011;61(4):426-30.
16. Sujata J, Safia R, Zeeba SJ. Morphological spectrum of endometrial pathology in middle aged women with atypical uterine bleeding: A study of 219 cases. Journal of Midlife Health. 2013;4(4):216-20.

17. Qing W, Li W, Jun S, Yan W, Li-Ping J, Da-Jin L, Ming-Qing L. L-22 enhances the invasiveness of endometrial stromal cells of adenomyosis in an autocrine manner. Int $\mathrm{J}$ Clin Exp Pathol. 2014;7(9):5762-71.

18. Shengtao Z, Tao Y, Rui L, Ce B, Xiaorong Q, Xiang H.. Proteomics identification of Annexin A2 as a key mediator in the metastasis and proangiogenesis of endometrial cells in human adenomyosis. Mol Cell Proteomics. 2012;11(7):M112.017988.

19. Tze-Sing H, Yi-Jen C, The-Ying C, Chih-Yao C, Hsin-Yang L, Ben-Shian H. Oestrogen induced angiogenesis by activating the slug-VEGF axis in endometrial epithelial cells.J.Cell Mol Med. 2014;18(7):1358-71.

20. Bergeron C, Amant F, Ferenczy. Pathology and physiopathology of adenomyosis.Best Pract Res Clin Obstet Gynecol. 2006;20(4):511-21.

Cite this article as: Sumathi S. Is adenomyosis, a frequent association of abnormal uterine bleeding? : a retrospective study on hysterectomy samples in the rural area of Melmaruvathur. Int J Reprod Contracept Obstet Gynecol 2016;5:1192-5. 